\title{
EDLC Type Supercapacitor Electrode Based on Banana Peels Activated Carbon
}

\author{
Alfiatur Rahmah ${ }^{1 *}$, Ahmad Zainollah ${ }^{1}$, Novi Artika Fitriani ${ }^{1}$, Dwi Sapri \\ Ramadhan ${ }^{2}$, Maf'ud Cahayo ${ }^{2}$, Masruroh ${ }^{3}$ \\ ${ }^{1}$ Undergraduate School of Department of Physics, Faculty of Mathematics and Natural Science, \\ Brawijaya University \\ ${ }^{2}$ Undergraduate School of Department of Chemistry, Faculty of Mathematics and Natural Science, \\ Brawijaya University \\ ${ }^{3}$ Department of Physics, Faculty of Mathematics and Natural Science, Brawijaya University \\ *Email: alfiaturrahmah1994@g mail.com
}

\section{ABSTRACT}

\begin{abstract}
The objective of this research is to observe the influence of surface area and porosity of banana peels activated carbon on the specific capacitance value as EDLC (Electrochemical Double Layer Capacitor) type supercapacitor electrode. Banana peels have been carbonated at temperature of $600^{\circ} \mathrm{C}$ and activated using $\mathrm{KOH}$ with concentrations of 5\%,15\%, 25\% and $35 \%$ at temperature of $700^{\circ} \mathrm{C}$. The activated carbon banana peels mixed with PVAc (Polyvinyl acetat), added with aquades and compressed on pressure of $80 \mathrm{kN}$. The specific capacitance has been carried out using galvano static method with $\mathrm{KOH} 30 \%$ as electrolyte solution. Pore size of membrane activated carbon was observed using Scanning Electron Microscopy (SEM) and Brunnuaer-Emmet-Teller (BET) method for surface area of activated carbon. The result shows that the optimum value at activation using $\mathrm{KOH} 25 \%$ with large surface area $540,454 \mathrm{~m}^{2} / \mathrm{g}$, porosity $17,89 \mu \mathrm{m}$ and specific capacitances of $72,93 \mathrm{~F} / \mathrm{g}$. The increase of large surface area and porosity activated carbon has affected to specific capacitance value, so activated carbon of banana peels potentials as electrode material supercapacitor EDLC type.
\end{abstract}

Keyword: activated carbon; porosity; specific capacitance; and supercapacitor electrode.

\section{INTRODUCTION}

In this modern era, the demand of highly efficient technology based on the recycling and reuse materials has been increased. One of the instance is the utilization of banana peels as a main component of an advanced electronic device. Banana peel contains 47,45\% carbon, $5,68 \%$ hydrogen, $0,37 \%$ nitrogen, $19,01 \%$ oxygen and $15 \%$ moisture ${ }^{[1]}$. This is based on innovation by changing the function of banana peels that is considered as waste into activated carbon that can be used as electrode material EDLC type supercapacitor.

Supercapacitor is an alternative energy storage device that has high energy density with the ability to store the large energy that designed to be more sustainable and friendly environmental. Supercapacitor has high power density, virtually unlimited life cycles, long shell life, fast charge, high efficiently, wide temperature operation range, safety and more life time than batteries ${ }^{[2-3]}$. Supercapacitor has been used extensively in many field, such as medical electronics, electrical utilities and transportation.

Currently, the electrode material of supercapacitor using porous carbon as natural ingredients with carbonization ${ }^{[4]}$. Activated carbon potentially used as an electrode material EDLC type supercapacitor because it has large surface area, high porosity and density, inexpensive, easy to process, stable electrochemical property and perfect cycle property [5-9]. The carbon structure, the porosity, and the surface area are the key to increase a specific capacitance 
value and the important properties for an ideal electrode material ${ }^{[10]}$. The surface area and porosity of activated carbon can be controlled with physical and chemical parameters such as annealing temperature and variety of activator.

In this research, we study on activated carbon made from banana (Musa paradisiaca L.) peels because it also contains organic compounds such as hemicellulose, lignin, and cellulose, which means it constitutes highly percentage of carbon chains [11]. Manufacture of banana peels activated carbon were processed by carbonization and activation using $\mathrm{KOH}$ because it can provide a large surface area and porosity of activated carbon [9]. To obtain an activated carbon with large surface area and porosity, we will make variety concentration of $\mathrm{KOH}$.

Activated carbon are used as electrode EDLC type supercapacitor. EDLC (Electrochemical Double Layer Capacitor) consists of two electrodes, a separator and an electrolyte solution. The specific capacitance is characterize using galvanostatic method. The specific capacitance value of EDLC type supercapacitor depends on the surface area, electrolyte solution and the pore-size distribution of activated carbon $[12,6,13]$. So, The Influence of surface area and porosity on specific capacitance of activated carbon banana peels will be studied and it will be the best activated carbon that can be used as material electrode for EDLC type supercapacitor.

\section{EXPERIMENTAL}

\section{Materials Electrode EDLC type Supercapacitor}

The materials had used in this research are banana (Musa paradisiaca L.) peels, $\mathrm{KOH}, 5 \mathrm{M}$ HCL, 0,5 gram PVAc and aquades. Banana peels has been activated at temperature of $600^{\circ} \mathrm{C}$ for two hours and sifted by a sieve of 400 mesh. The activated carbon was activated by $\mathrm{KOH}(5 \%, 15 \%, 25 \%$ and $35 \%$ concentrations) with activation temperature of $700^{\circ} \mathrm{C}$. Variety concentration of $\mathrm{KOH}$ were aimed to know the difference of surface area and porosity of activated carbon. Activated carbon was immersed into a solution of $5 \mathrm{M} \mathrm{HCL}$ until the solution became yellow and colorless. It was cleaned by aquades and heated at temperature of $120^{\circ} \mathrm{C}$. Activated carbon, PVAc 0,5 gram and aquades $10 \mathrm{~mL}$ were mixed to press with pressure $80 \mathrm{kN}$. The resulting mixture are ready to characterize by Scanning Electron Microscopy (SEM) and Quantachrome Autosorb Automated Gas Sorption Analyzer using Brunnuaer-Emmet-Teller (BET) method.

\section{Specific Capacitance Assay of EDLC type Supercapacitor Electrode}

To measure the electrochemical performance of activated carbon, two pellet of activated carbon were affixed to $\mathrm{Cu}$ as current collector with polypropylene as a separator. Before $\mathrm{Cu}$ was used, it has been activated with $\mathrm{KOH} 7 \%$ and heated at temperature of $120^{\circ} \mathrm{C}$ for one hour. The component of supercapacitor was immersed in $\mathrm{KOH} \mathrm{35 \%} \mathrm{solution} \mathrm{and} \mathrm{the} \mathrm{specific}$ capacitance was observed by using galvanostatic method. Specific capacitance of activated carbon was calculated by $E(t)$ slope ${ }^{[14,9]}$ :

$$
C=\frac{2 I t}{m \Delta E}
$$

Where $I$ is the discharge current, $t$ is the discharge time, $m$ is the mass of carbon on an electrode, and $\Delta E$ is the voltage drop in discharge. 


\section{RESULTS AND DISCUSSION}

\section{Physical Parameter of Banana Peels Activated Carbon}

The characterization results of banana peels activated carbon using Scanning Electron Microscopy (SEM) with a magnification $4000 \mathrm{X}$ reveals that surface roughness is a function of $\mathrm{KOH}$ concentration. At $\mathrm{KOH}$ concentration of $5-25 \%$, it is observe that surface roughness is proportional to $\mathrm{KOH}$ concentrations. The surface roughness itself impacts the activated carbon's porosity. The quantitative relations between $\mathrm{KOH}$ concentration and porosity is as follows: activated carbon with $\mathrm{KOH} 5 \%, 15 \%$, and $25 \%$ has largest porosity $6,86 \mu \mathrm{m}, 8,21 \mu \mathrm{m}$, and $17,89 \mu \mathrm{m}$ while at $35 \%$ has largest porosity of $12 \mu \mathrm{m}$.
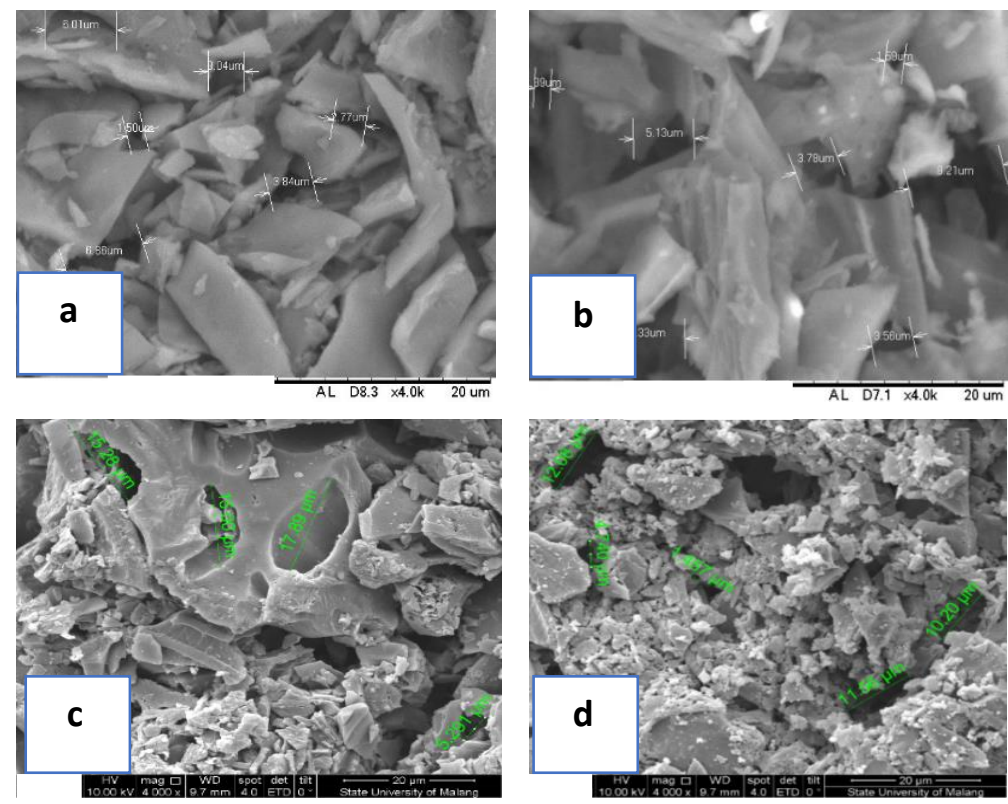

Figure 1. (color online) The morphology of surface activated carbon; a) $\mathrm{KOH} \mathrm{5 \% ;} \mathrm{b)} \mathrm{KOH} \mathrm{15 \% ;} \mathrm{c)} \mathrm{KOH} \mathrm{25 \% ;} \mathrm{and} \mathrm{d)}$ $\mathrm{KOH} 35 \%$

The results of surface area calculation using BET method showed that the greater porosity (pore size) of activated carbon then the greater surface area of activated carbon as shown in Table 1 . In this research, we used Nitrogen gas as adsorbat.

Table 1. TheBrunnuaer-Emmet-Tellermethod results of banana peels activated carbon.

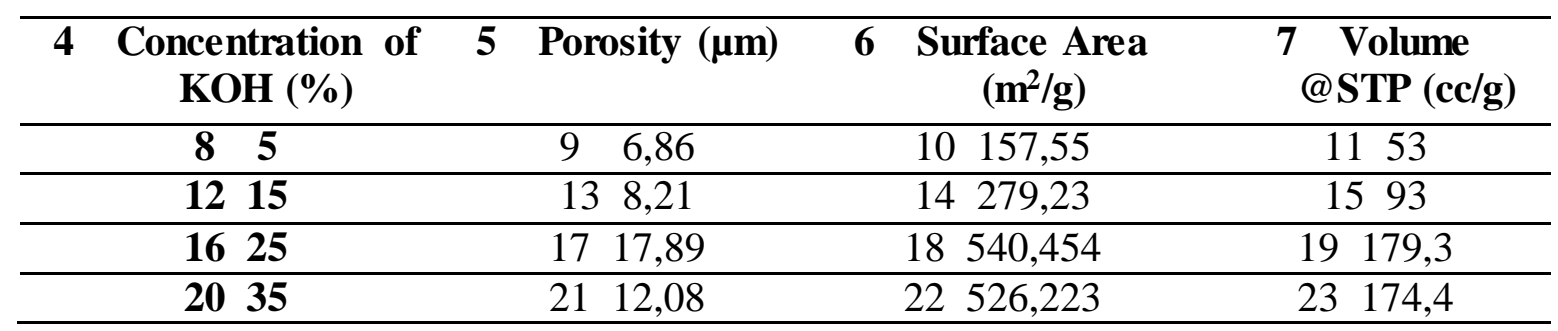

Based on Table 1, it is inferred that the larger surface area of banana peels activated carbon, is proportional to the amount of Nitrogen gas adsorbed, since more active sites formed on activated carbon capable to bind Nitrogen gas. The graph of adsorption of Nitrogen gas after characterized using Brennuer-Emmet-Teller method as shown in Figure 2. 


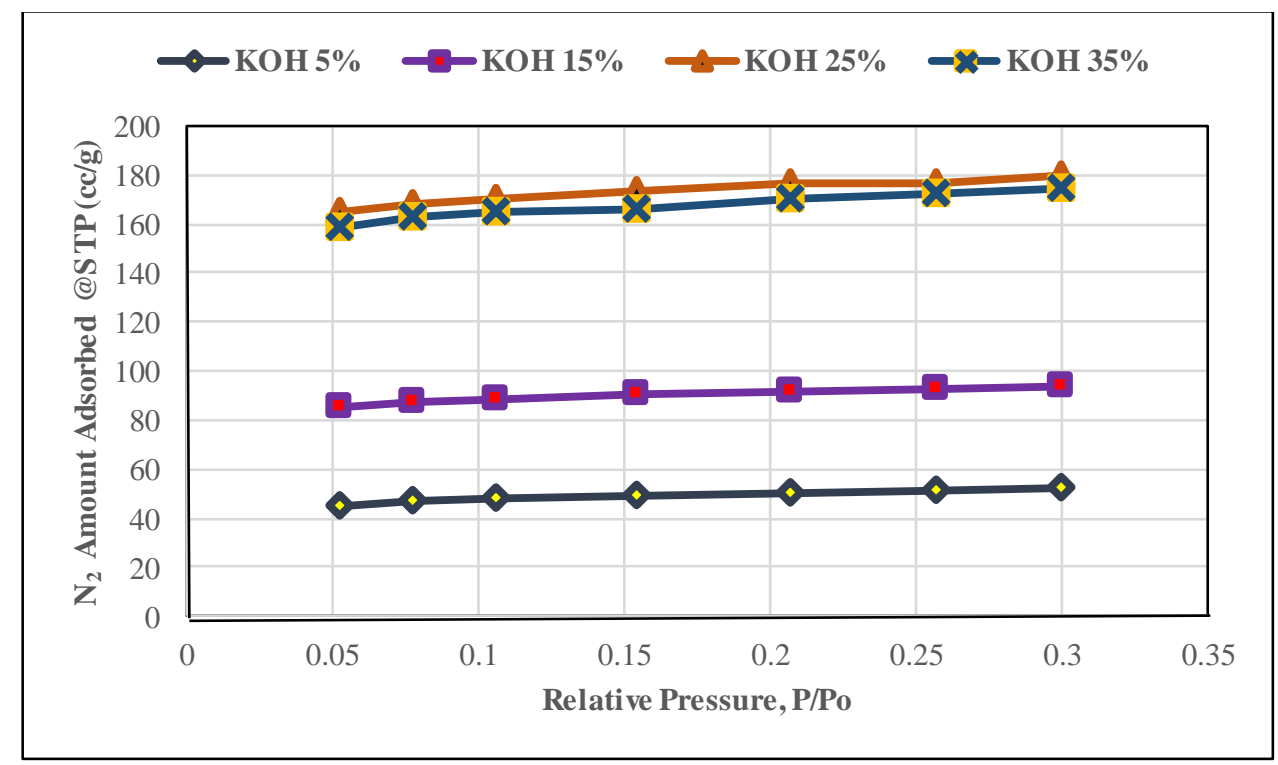

24

25 Figure 1. (color online) Isothermsof banana peels activated carbon

Isotherm curve on Figure 2 shows that Nitrogen gas adsorption on banana peels activated carbon is classified as type I adsorption according to IUPAC classification which is occurred on micropore materials $(<2 \mathrm{~nm})$. Based on Figure 2, it can be noted that banana peels activated carbon adsorbs Nitrogen gas at the maximum when the relative pressure is $0,3 \mathrm{P} / \mathrm{Po}$ and the maximum absorption volumes of $53 \mathrm{cc} / \mathrm{g}(\mathrm{KOH} 5 \%), 93 \mathrm{cc} / \mathrm{g}(\mathrm{KOH} 15 \%), 179,3$ $\mathrm{cc} / \mathrm{g}(\mathrm{KOH} 25 \%)$, and $174,4 \mathrm{cc} / \mathrm{g}(\mathrm{KOH} 35 \%)$ are obtained. From this experimental results, it can be conclude that the greater porosity of activated carbon than the greater surface area and the adsorption power possessed by activated carbon. The large surface area and porosity of activated carbon affects the specifics capacitance value of EDLC type supercapacitor.

\section{The Specifics Capacitance Value of the Banana Peels Activated Carbon}

In this research, banana peels activated carbon is convert into electrode of EDLC type supercapacitor and acts as a site of an electrochemical reaction. When charging process begin, occurs ions exchange from the two electrodes passing through a separator. The surface area and porosity formed affects the accessibility of ions onto surface of electrode in the process, and the charges are then stored in the electrode, which in returns generates electric field and measurable value of capacitance ${ }^{[23]}$. The specific capacitance of EDLC type supercapacitor is affected by electrolyte solution, surface area, and porosity of activated carbon. Ion accessibility in activated carbon with less porosity is more difficult compared to the case in activated carbon with larger value of porosity.

The value of specific capacitance obtained by $\mathrm{KOH}$-activated carbon are $14,5 \mathrm{~F} / \mathrm{g}(\mathrm{KOH}$ $5 \%$ ), 31,89 F/g (KOH 15\%), 72,89 F/g (KOH 25\%), and 42,03 F/g (KOH 35\%). The graphical relationship between the specific capacitance, porosity, and $\mathrm{KOH}$ concentration is presented by following Figure 3. 


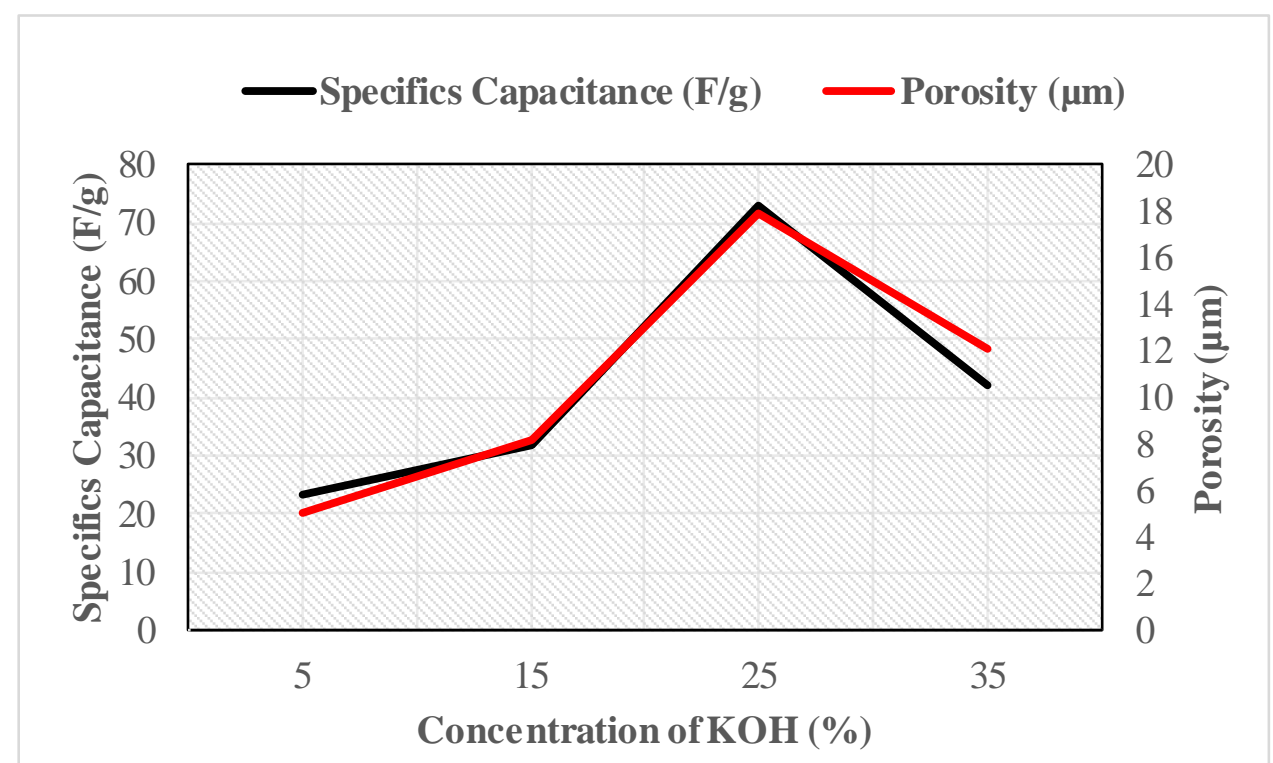

Figure 3. (color online) The relationship of specific capacitance and porosity of activated banana peels.

These resultalso in good agreement with SEM (Figure 1) and BET method analysis (Table 1). High porosity and surface area of banana peels activated carbon makes as higher a specific capacitance value. Therefore, preparing activated carbon pore structure, porosity and high surface area is important in preparing the electrode material EDLC type supercapacitor.

\section{CONCLUSION}

The effect of surface area and porosity of banana peels activated carbon on the specific capacitance value as EDLC type supercapacitor electrode have been observed. The results shows that the optimum value of porosity $(17,89 \mu \mathrm{m})$ occurs at activation with $\mathrm{KOH} 25 \%$ with surface area of $540,454 \mathrm{~m}^{2} / \mathrm{g}$ and gives specific capcitance $72,93 \mathrm{~F} / \mathrm{g}$. It is therefore concluded that banana peels activated carbon is highly potential to be an electrodematerial of EDLC-type supercapacitor.

\section{ACKNOWLEDGEMENT}

The authors would like to say thanks to DITJEN DIKTI who have financed this research in grants PKM (Program Kreativitas Mahasiswa) 2015 program. 


\section{REFERENCE}

1 Wilaipon, Patomsok. 2009. The Effects of Briquetting Pressure on Banana-Peel Briquette and the Banana Waste in Northen Thailand. American Journal of Applied Science. 6 (1): 167-171.

2 Zhao, Cuimei., and Zheng, W. 2015. A Review for Aqueous Electrochemical Supercapacitors. Frontiers in Energy Research. 3(23): 1 - 11.

3 Gouws, R., and Elizbe, V.N. 2013. Prototype Super-Capacitor Photovoltaic Streetlight with $\mathrm{x}$ Logic Super Relay Functionality. International Journal of Emerging Trends in Electrical and Electronics. 7(1): 34-39

4 Miller, J.R., and Simon P. 2008. Supercapacitors: Fundamentals of Electrochemical Capacitor Design and Operation. The Electrochemical Society Interface.

5 Frackowiak, E., and Béguin, F. 2001. Carbon Materials for the Electrochemical Storage in Capacitors. Carbon. 39: 937-950.

6 Shi, Hang. 1996. Activated Carbons and Double Layer Capacitance. Electrochimica Acta. 41(10): 1633-1939.

7 Kötz, R, and Carlen, M. 2000. Principle and Applications of Electrochemical Capacitor.ElectrochimicaActa. 45(15-16): 2483-2498.

8 Zhang, L.L, and Zhao, X.S. 2009. Carbon-based Materials as Supercapacitor Electrodes. Chem.Soc.Rev. 38(9): 2520 - 2531.

9 Liu, Y.X., Li, J., Lai, Y.Q., Song, H.S., and Zhang, Z. 2007. Preparation and Properties of Pitch Carbon Based Supercapacitor. J. Cent, South Univ. Technol. 14(5):-.

10 Chen, T., and Dai, L. 2013. Carbon Nanomaterials for High-Performance Supercapaccitors. Materials Today. 16(7/8): 272-280

11 Emaga, T.H., Robert, C., Rongkart, S.N., Wathelet, B. and Paquot, M. 2008. Dietary Fiber Components and Pectin Chemical Features of Peels during Ripening in Banana and Banana Varieties. Bioresource Technology 99. (10): 4346-4354

12 Huang H.C., Cheng-wei, H., Chien-Te H., and Hsisheng, T. 2014. Electrical Double Layer Capacitors of High Volumetric Energy Based on Ionic Liquids and Hierarchical-pore Carbon. Journal of Materials Chemistry A.

13 Jayalakshmi, M., and Balasubramanian, K.2008. Simple Capacitors to Supercapacitors- An Overview. Int. J. Electrochem. Sct,. 3: 1196-1217.

14 Portet, C., Taberna, P.L., Simon, P., Labety, R. 2004. Modification of Al Current Collector Surface by Sol-gel Deposit for Carbon-carbon Supercapacitor Application. ElectrochimicaActa. 49(-): 905-912 